\title{
PROCESO PRODUCTIVO, CRECIMIENTO \\ Y DISTRIBUCIÓN DE POBLACIÓN EN LA ZONA DE INFLUENCIA DEL INGENIO EMILIANO ZAPATA*
}

\author{
Crescencio Ruiz Chiapetto \\ El Colegio de México
}

\section{INTRODUCCIÓN}

EN el Centro-sur del estado de Morelos, cerca de Cuernavaca y Cuautla -las dos principales ciudades del estado - se distribuye la población, dedicada principalmente al cultivo de la caña de azúcar, alrededor de tres pequeñas ciudades: Zacatepec, Jojutla y Tlaquiltenango (véase el mapa 1). La cercanía que guardan estas ciudades entre sí ha integrado sus actividades predominantes formando el conjunto agro-industrial que requiere el cultivo de la caña. Tlaquiltenango, esencialmente agrícola, es una de las localidades de la región que contribuyen con mayor cantidad de caña al ingenio Emiliano Zapata. Este ingenio, localizado en Zacatepec, da un carácter eminentemente industrial a la ciudad; en ella se realizan las actividades técnicas y administrativas encaminadas al procesamiento de la caña de azúcar. Por último, Jojutla es el centro comercial y recreativo de la región, con actividades industriales relacionadas con el cultivo del arroz.

Esas tres ciudades son el centro de la región (formada por diecisiete municipios) que abastece de caña al ingenio Emiliano Zapata. El análisis del crecimiento y distribución de la población de esta región es el objeto de este estudio.

\section{ANTECEDENTES}

1. Selección y delimitación de la región de estudio

En un trabajo anterior definimos cinco zonas agrícolas en el país -a

* Este trabajo cubre parte de la segunda etapa del proyecto de investigación "Análisis de los cambios demográficos en diferentes contextos socioeconómicos agrícolas de México", que se realiza en el Centro de Estudios Económicos y Demográficos de El Colegio de México. Agradezco a José Macías y José Luis Palma por su ayuda en la elaboración de los datos, y a Rosa María. Rubalcava por su auxilio en el planteamiento del Apéndice Metođológico. 
nivel municipal en el año de 1970 - con base en las siguientes variables que proporcionan los Censos Agrícolas y de Población: $i$ ) predominio de predios con alto o bajo valor de la producción agrícola respecto a la del municipio (VPA); ii) energía empleada en las unidades productivas del municipio (mecánica, animal o mixta), y iii) nivel de participación del trabajo asalariado en las actividades agrícolas del municipio. ${ }^{1}$ Las zonas I y II fueron aquellas donde predominaron los predios de alto valor de la producción, la energía mecánica y el trabajo asalariado. Las zonas IV y $\mathrm{V}$ se caracterizaron por predios de bajo valor de producción, energía animal y trabajo familiar. Por último, como zona III se clasificaron los municipios donde los valores de las variables utilizadas no tuvieron una asociación uniforme. El primer tipo de zonas (I y II) puede tomarse como de alto nivel de desarrollo, el segundo (IV y V) como de bajo nivel de desarrollo y el último (III) como de nivel medio o de carácter heterogéneo.

Con base en esta zonificación seleccionamos la región de estudio. Dos criterios -quizá arbitrarios - fueron considerados en esta selección: $i$ ) para que el primer estudio de caso en la investigación no sufriera un sesgo interpretativo, se eligieron algunos municipios de las zonas de tipo intermedio (zona III). Se consideró que de esta manera podría evitarse que el desarrollo del proyecto enjuiciase al sector agrícola en México exclusivamente a partir de uno de sus extremos: sector capitalista o sector campesino; ii) para facilitar el trabajo de campo se decidió trabajar con municipios de la zona III cercanos a la ciudad de México, a pesar de la influencia que ésta pudiera ejercer sobre la región de estudio. Con base en esos criterios se escogieron como punto de partida cuatro municipios del estado de Morelos; luego de una serie de visitas a esa zona se delimitó la región final de estudio.

La base teórica e instrumental para la delimitación de regiones agrícolas es conocida: con un criterio de homogeneidad se distinguen entre ellas mediante la elaboración de índices. ${ }^{2}$ Se ha insistido, es cierto, en la conveniencia de tratar a las regiones como subsistemas, aunque difícilmente se señalan formas de hacerlas operacionales. Para delimitar nuestra región de estudio nos propusimos este último criterio -región como subsistema-, por lo que la forma de instrumentarlo tuvo un carácter eminentemente heurístico.

Al tomar como punto de partida una región definida en forma preliminar, con base en información muy simple de carácter censal, y con hipotesis generales respecto a las relaciones que podrían descubrirse en el proceso productivo, se consideró que algunas visitas al campo darían un criterio final para definir la región de estudio. Brevemente se mencionan estos pasos:

${ }^{1}$ C. Ruiz Chiapetto, "Caracterización de zonas para el estudio de la dinámica demográfica en el sector agrícola: México, nivel municipal, 1970", Centro de Estudios Económicos y Demográficos, El Colegio de México, 1976 (mimeografiado).

2 Véase J. G. M. Hilhorst, Regional Planning, Rotterdam University Press, 1971. 
a) Información previa a la visita de campo. Los cuatro municipios seleccionados - Jojutla, Tlaltizapán, Tlaquiltenango y Zacatepec- presentaban las siguientes características en la zonificación antes mencionada: predominio de predios de bajo valor de la producción, energía mecánica y una elevada proporción de trabajo asalariado. $\mathrm{O}$ sea, que con excepción de la primera variable, las demás correspondían a un alto nivel de desarrollo.

La información censal indicaba también que los cultivos predominantes en esos municipios eran la caña de azúcar, el arroz y el maíz; que se trataba de una zona con tenencia de la tierra eminentemente ejidal, y con una dispersión de población moderada que mantenía un alto crecimiento.

b) Hipótesis. La literatura de tipo teórico que hay sobre el sector agrícola - en especial la que discute la forma de producción campesina de los países menos desarrollados- es francamente abrumadora." Sin embargo, esta discusión teórica pocas veces se ha reflejado en nuevos marcos operacionales. De una manera o de otra, se vuelve al trabajo clásico de Lenin sobre el proceso de diferenciación del campesinado - “"descampesinización"-, y a los indicadores por él propuestos cuando se llega al nivel de la cuantificación. ${ }^{4} \mathrm{El}$ caso que estudio aquí, no es diferente.

Bajo el supuesto de que algunas de las características del proceso de diferenciación de los campesinos ${ }^{5}$ podrían delimitarse espacialmente, y sin olvidar que el punto de partida - y la meta - es la población, ${ }^{6}$ se realizaron las visitas a un pequeño número de localidades de los municipios seleccionados.

c) La población de la región, como se ha dicho, gira alrededor del cultivo de la caña. Para este cultivo, en México, se han definido oficial-

3 Un buen resumen de esta literatura puede verse en: M. P. L. Martínez, K. A. de Appendini, V. A. Salles y T. Rendón, "La economía campesina: consideraciones téricas y análisis preliminar de una encuesta en 13 pueblos de México", El Colegio de México, 1976 (mimeografiado).

4 V. I. Lenin, El desarrollo del capitalismo en Rusia, Buenos Aires, Ediciones Estudio, 1973.

5 El proceso de diferenciación se expresa, por una parte, en la constitución de distintos tipos de campesinos: burguesía rural o campesinos acomodados, proletario rural (jornaleros) y campesinos medios; por otra, se expresa en un proceso de proletarización que se genera por la reducción constante de los campesinos medios. Esto, según Lenin, puede demostrarse por el aumento progresivo en el empleo de maquinaria y de trabajo asalariado (ibid., pp. 180-194 y 220).

6 "Parece justo comenzar por lo real y lo concreto, por el supuesto efectivo; así, por ejemplo, en la economía, por la población que es la base y el sujeto del acto social de la producción en su conjunto. Sin embargo, si se examina con mayor atención, esto se revela [como] falso. La población es una abstracción si dejo de lado, por ejemplo, las clases de que se compone. Estas clases son, a su vez, una palabra vacía si desconozco los elementos sobre los cuales reposan, por ejemplo, el trabajo asalariado, el capital, etc.... Si comenzara, pues, por la población, tendría una representación caótica del conjunto $y$, precisando cada vez más llegaría analíticamente a conceptos más simples... Llegando a este punto, habría que reemprender el viaje de retorno, hasta dar de nuevo con la población..." $\mathbf{K}$. Marx, Introducción general a la crítica de la economía política/1857, 6a. edición, Córdoba, Cuadernos de Pasado y Presente, 1, 1972, p. 21. 
mente zonas de abastecimiento para cada ingenio (Cf. infra, p. 247). En el recorrido a la región pudo obtenerse información aproximada de las localidades que abastecen con caña al ingenio E. Zapata. Con base en esa información se definió como región de estudio a los municipios que contenían, al menos, una localidad dedicada al cultivo de la caña. Con este criterio la zona por analizar quedó comprendida por 17 municipios del estado de Morelos." (véase el mapa 1').

\section{Mapa 1}

EsTado DE MORELOS: UBICACIÓN DE LA ZONA DE ESTUdio



MUNICIPIOS DE LA ZONA DE ESTUDIO

I. Amocuzoc

2. Villo de Ayola

3. Cootlón del Río

4. Emiliano Zapata

5. Jiutepec

6. Jojutio

7. Jonacaitepec

8. Mazatepec

9. Miacotlón

10. Puente de $|x| 10$

11. Temixco

12. Tepolcingo

13. Tetecolo

14. Tlaltizopoin

i5. Tlolquitenango

16. Xochitepec

17. Zacofepec

2. Cultivo de la caña: proceso productivo y ajustes institucionales

El requisito técnico-ecológico para la producción del azúcar es que haya grandes extensiones de tierra, de cierta calidad y que se localicen

7 La zona de abasto del ingenio Emiliano Zapata comprende también algunas localidades de los municipios de Malinalco - estado de México-, y de Buenavista de Cuéllar -estado de Guerrero-. Como la participación de estas localidades en el abastecimiento de caño no ha sido constante, se decidió trabajar en exclusiva con municipios del estado de Morelos. Se considera que esta delimitación no afecta, sino que facilita el análisis de las características de la zona. Otros estudios analizan sólo los municipios predominantemente cañeros; véase por ejemplo, W. H. Barreda, $R e$ cursos naturales y humanos de las zonas cañeras más importantes de México, Banco de México, S. A. Departamento de Investigaciones Industriales, s.f. En este trabajo se estudian sólo 11 municipios del estado de Morelos. 
alrededor de un ingenio que se encarga de procesar la caña. La extensión de esas tierras puede variar según la capacidad instalada del ingenio, pero no pueden estar demasiado alejadas del mismo, ya que el aprovechamiento de la caña, una vez cortada, disminuye de manera notable con el tiempo. Es decir, el proceso productivo requiere que las actividades agrícolas e industriales estén espacialmente unidas.

Esta cercanía espacial hace más evidente la manera en que las actividades económicas generan una profunda diferenciación social. La primera de esas diferencias resulta de la necesidad del control global del proceso productivo. Como éste requiere, por una parte, que una cantidad apreciable de tierras con restricciones de calidad y localización se dedique casi en exclusiva al cultivo de la caña, y por otra, que el corte y el procesamiento del producto estén coordinados de manera adecuada, existe la necesidad de un control unitario sobre todo del proceso productivo. Control que dará a quienes lo ejercen un lugar preponderante en la escala social de la región.

Dentro del ámbito de las actividades agrícolas, los requerimientos de mano de obra en las tareas del cultivo de la caña pueden desarrollar otro tipo de diferenciación social. En estos términos -absorción de mano de obra en las tareas del cultivo- se presentan dos etapas más o menos definidas: una que va desde la siembra hasta antes del corte, que tiene por objeto asegurar el mejor crecimiento de la planta (en las labores de raspadillas, riegos, fertilizantes, etc.), ${ }^{8}$ y que requiere pocas jornadas de trabajo de mediana calificación; otra, que consiste en el corte y traslado de la caña al ingenio y que requiere un uso intensivo de mano de obra sin calificación. Cuando estas tareas no las realiza el mismo grupo de población, sino que se dividen entre cultivadores y cortadores, se produce una diferenciación social entre ellos ya que en la tarea del corte de caña se encuentran los trabajadores en las peores condiciones de vida (baja remuneración, garantías ínfimas de trabajo, población inmigrante, etc.)..$^{9}$

En relación al objeto de estudio -estructura agraria y dinámica de la población-, el efecto más visible de los requerimientos de mano de obra

${ }^{8}$ Véase Cooperativa de Ejidatarios y Obreros del Ingenio del Mante, S. C. L., Problemas y proyectos del ingenio del Mante, A.B. C., Ciudad Mante, Tamps. México, 1952.

9 'Se ha afirmado que la separación de tareas entre cultivadores y cortadores no afecta la pertenencia a la "clase social" trabajadora, véase $L$. $H$. Barjau, "Las migraciones al ingenio de Motzorongo, Veracruz", Tesis. México, Escuela Nacional de Antropología, 1972 (mimeografiado). No se utiliza el término "clase", no sólo por los problemas teóricos que acarrea el concepto, sino también por la poca utilidad que tiene para analizar la cuestión campesina ("... saber si los campesinos son o no son una clase, una capa o una estratificación social es una pedantería escolástica. El carácter del campesino no debe ser buscado al nivel de lo que es, o de lo que debe ser en función de las categorías del modo de producción capitalista. Por el contrario, dicho carácter puede ser definido al nivel de su existencia social, de sus relaciones con el conjunto del sistema social" K. Vergopoulos, "El capitalismo disforme" en S. Amin y K. Vergopoulos, La cuestión campesina y el capitalismo, México, Ediciones Nuestro Tiempo, 1975, pp. 215-216. 
por el cultivo de la caña es una alta densidad de población en las zonas de cultivo. Esta densidad puede ser permanente o periódica (ciclos del cultivo), según se cubran los requerimientos de mano de obra con población nativa o migrante.

En el primer caso, cuando la población nativa es numerosa, la mano de obra durante el periodo del cuidado de la caña puede dedicarse a otros cultivos, y en la época de zafra -época de secas de los otros cultivoscontratarse como cortador. Esta posibilidad sólo es efectiva si los arreglos institucionales impiden al trabajador obtener ingresos suficientes de los cultivos complementarios al de la caña. En el segundo caso, cuando la población nativa no proporciona la mano de obra necesaria para la época de zafra - ya sea porque es poco numerosa, o porque obtiene ingresos suficientes de otros cultivos-, se recurrirá periódicamente a mano de obra migrante. Es decir, en uno y otro caso el crecimiento de la población responderá a pautas más o menos uniformes.

Por último, las actividades industriles del proceso productivo, es decir las labores del ingenio, dan lugar a un nuevo tipo de trabajadores en las zonas cañeras: los obreros. Este tipo de trabajadores ha ganado importancia con el tiempo, ya que, por una parte, el progreso tecnológico ha permitido una mayor escala de producción, lo que se ha traducido en un mayor número de obreros, y por otra, el mismo avance tecnológico ha generado una mayor especialización, y, en consecuencia, una mayor dificultad en el traslado de trabajadores de una rama de actividad a otra. Esta distinción entre obreros y cultivadores puede dar lugar a una nueva diferenciación social en el proceso productivo.

Por lo que hace a la distribución de población, su concentración o dispersión dependerá de las actividades industriales —número y escala de producción de los ingenios. Es decir, una ciudad mediana o varias pequeñas servirán como "lugar central" de un mayor o menor número de localidades dedicadas al cultivo de la caña.

En lo que toca a los organismos que administran el cultivo de la caña, sabemos que la necesidad de controlar el proceso productivo en sus distintas etapas - con requisitos técnicos, ecológicos y humanos diferentes-, ha dado lugar a marcos institucionales más o menos específicos en diferentes épocas. Mintz, por ejemplo, señala para el caso de Puerto Rico tres formas de organización en distintos periodos: el de plantación, basado en el trabajo de esclavos y agregados, el de la hacienda familiar, y el más reciente, de corporaciones agroindustriales. ${ }^{10}$

Estas formas de organización se dan - aunque no con esa claridaden el caso de México. En el siglo xvi, por ejemplo, se recurría a la compra de esclavos para cubrir necesidades de mano de obra, ya que los avatares de la conquista habían producido una reducción de la población

10 S. W. Mintz, "The Culture History of a Puerto Rico Sugar Cane Plantation: 1876-1949", The Hispanic American Historical Review, Vol. 33, 1953, pp. 224-251 
indígena. ${ }^{11}$ Pero en México ese tipo de mano de obra (esclavos) no llegó a ocupar un primer plano en la población activa. En los siglos siguientes, cuando se va cimentando la organización de la hacienda en el cultivo de la caña, se utiliza mano de obra indígena. A diferencia del siglo XVI, se dio el caso de que, especialmente en los siglos XVIII y XIX, el alto crecimiento de la población aborigen comenzó a ejercer presión sobre la tierra (pueblos vs. hacendados), que desembocó en la violencia de principios del siglo $\mathrm{XX}$.

En decenios recientes, la industria azucarera entra en una etapa de modernización que se desarrolla dentro de las características a que dio lugar la Reforma Agraria, en lo que se refiere a la tenencia de la tierra; al mismo tiempo se halla circunscrita a la forma de organización que se genera en la industria por la participación gubernamental en ella.

En este trabajo se analiza esta última etapa de la zona de estudio seleccionada.

\section{Región DE ESTUdio: CRECIMIENTO Y DisTRIBUCIÓN DE POBLACión}

Zapata es asesinado en Chinameca - municipio de Ayala- en abril de 1919, y su muerte pone fin, en cierta forma, a un proceso de despoblamiento que se venía produciendo desde 1911 en el estado de Morelos. El despoblamiento se acentuó sobre todo en los años 1912-1913, cuando la estrategia de la lucha contra el campesinado zapatista se sustenta en la "recolonización" (la quema de pueblos), y en la leva (reclutamiento involuntario), lo que resulta en una disminución sustancial en el número de localidades y en una emigración forzosa y masiva..$^{12}$ En 1910, Morelos tenía 290 localidades y para 1921 éstas habían disminuido a 230. En términos del volumen total de población esta disminución significó casi un 50\%. De 179000 a 103000 habitantes. La entidad tardaría 20 años en recuperar el volumen de población que tenía en 1910 (Censos de población).

En lo que sigue, sin analizar las causas de la lucha campesina, se trata de relacionar esos fenómenos de despoblamiento y poblamiento a través del proceso productivo de la caña de azúcar.

Al finalizar el siglo XIX, Morelos era el mayor centro productor de azúcar en México. A partir de 1870-1880, el grupo de hacendados que manejaba las principales haciendas comienza a introducir mejoramientos tecnológicos en el procesamiento de la caña con el fin de aumentar la escala de producción; esto significaba, necesariamente, ampliar la superficie hasta entonces dedicada al cultivo de la caña. La ampliación de tierras se realiza mediante la compra de terrenos a los pueblos - las que

11 Véase W. Barrett, The Sugar Hacienda of the Marqueses del Valle, University of Minnesota Press, Mineapolis, 1970, pp. 74-92.

12 Véase J. Womack Jr., Zapata y la revolución mexicana, México, Siglo XXI Editores, 7a. edición, 1976, pp. 156-166. 
se llevan a cabo más por apoyo gubernamental que por la voluntad de los propietarios-, lo que da lugar a una desintegración paulatina del campesino medio. Vendida su tierra, el campesino se ve obligado a vender su fuerza de trabajo a la hacienda o a migrar a otras regiones, hasta que este proceso de proletarización se ve interrumpido por el levantamiento de Emiliano Zapata. (ibid., pp. 36-65).

$\mathrm{La}$ violencia producida por este levantamiento se reflejó en una disminución notable de la producción de azúcar en la entidad debido a la pérdida de control del proceso productivo por parte de los hacendados, y aun cuando hubo intentos para no detener la producción (cuando los militares intervinieron las haciendas en 1914 y cuando las restituyeron en 1919 a los hacendados), ésta no pudo continuar debido a la dificultad de asegurar el volumen de mano de obra que requería el cultivo de la caña (ibid., pp. 231-347). La reducción de población en esos años fue una limitante para reanudar la producción de azúcar en la zona. Es sólo hasta el decenio de los cuarenta, con la inaguración del ingenio Emiliano Zapata en el municipio de Zacatepec y dentro de un nuevo marco institucional, que se vuelve al cultivo de la caña en una de las regiones más importantes en la entidad.

\section{Cambios en la distribución de población 1921-197013}

En 1921 la zona que llegaría a abastecer al ingenio Emiliano Zapata había sufrido las consecuencias del movimiento campesino. En 1910 existían 165 localidades en la región y para 1921 habían disminuido a 107. El número de las localidades de 1910 fue alcanzado sólo hasta los años sesenta (véase el cuadro 1 ). Sin embargo, esto no significa que el crecimiento de población haya sido lento en el periodo 1921-1970, por el contrario, se trata de una de las zonas rurales de mayor crecimiento en el país, crecimiento que ha sido acompañado de un cambio sustancial en las pautas de distribución de población en la región.

Al finalizar el año de 1920 — con Obregón en el poder - la paz vuelve a Morelos y, como resultado del movimiento zapatista, es la primera entidad federativa donde comienza a plantearse la posibilidad de una política agraria encaminada a la restitución de pueblos y dotación de ejidos (Womack, op. cit. pp. 359-364). Es posible suponer que, en 1921 - cuando esa política no había generado un cambio notable en la tenencia de la tierra - la población de la región estuviera distribuida aún con las antiguas normas de la época de la hacienda. Así parece confirmarlo la información censal: los municipios donde se encontraban las principales haciendas -Ayala, Jonacatepec, Miacatlán, Xochitepec-, así como

13 La región de estudio fue delimitada con base en información censal de 1970 , y quedó comprendida por 17 municipios (Cf. supra, p. 232). En este apartado se hace referencia a los patrones de distribución de población de estos municipios en 1921, 1940 y 1970. Cabe señalar que tres de éstos no tenían esa categoría en 1921: Emiliano Zapata, Temixco y Zacatepec (véase el mapa 2). 
Cuadro 1

Zona de INFluencia DEL INGENIo Emiliano Zapata:

DisTRIBUCIÓN DE LA POBLACIÓN POR TAMAÑO DE LOCALIDADES,

$1921-1970$

\begin{tabular}{|c|c|c|c|c|c|c|c|c|c|}
\hline \multirow{2}{*}{$\begin{array}{l}\text { Grupos de looalida } \\
\text { des aesin el tamá } \\
\text { no do la población } \\
\text { (número de habitan } \\
\text { tes) }\end{array}$} & \multicolumn{3}{|c|}{1921} & \multicolumn{3}{|c|}{1940} & \multicolumn{3}{|c|}{1970} \\
\hline & $\begin{array}{l}\bar{M} \text { Mumero } \\
\text { de to } \\
\text { calida } \\
\text { des. }\end{array}$ & $\begin{array}{l}\text { Poblaoion } \\
\text { (habitan- } \\
\text { tes) }\end{array}$ & $\begin{array}{l}\text { \% do po } \\
\text { blaoion } \\
\text { da la } \\
\text { zona }\end{array}$ & $\begin{array}{l}\text { Mumaro } \\
\text { de 10 } \\
\text { caltda } \\
\text { dea }\end{array}$ & $\begin{array}{l}\text { Población } \\
\text { (habitan- } \\
\text { tes) }\end{array}$ & $\begin{array}{l}\text { 产 de po } \\
\text { blacion } \\
\text { de } 1 \mathrm{a} \\
\text { zona }\end{array}$ & $\begin{array}{l}\text { Numero } \\
\text { de } 10 \\
\text { oaldada } \\
\text { dos }\end{array}$ & $\begin{array}{l}\text { Poblacion } \\
\text { (habitan- } \\
\text { tes) }\end{array}$ & $\begin{array}{l}\text { Todo po } \\
\text { blaojon } \\
\text { de la } \\
\text { zona }\end{array}$ \\
\hline Total de la zona & 107 & 48939. & 100.00 & 142 & 83378 & 100.00 & 186 & 261565 & 100.00 \\
\hline D. 1 a 99 & 20 & 1116 & 2.28 & 16 & 886 & 1.06 & 19. & 1033 & 0.39 \\
\hline De 100 a 499 & 52 & 13437 & 27.46 & 64 & 17073 & 20.48 & 68 & 18885 & 7.22 \\
\hline De 500 a 999 & 13 & 8536 & 17.44 & 33 & 22963 & 27.54 & 32 & 23426 & 8.96 \\
\hline De 1000 a 2499 & 10 & 15982 & 32.65 & 14 & 24052 & 28.85 & 38 & 60949 & 23.30 \\
\hline De 2500 a 4999 & 2 & 6234 & 12.74 & 5 & 15983 & 19.17 & 17 & $: 60 \cdot 166$ & 23.00 \\
\hline De 5000 a 9999 & - & - & - & - & - & - & 8 & 54.942 & 21.01 \\
\hline De 10000 a 20000 & - & - & - & - & - & - & 3 & 41.712 & 15.95 \\
\hline No sapeoificadas & 10 & 3634 & 7.43 & 10 & 2421 & 2.90 & 1 & 452 & 0.17 \\
\hline
\end{tabular}

Fuente: Cálculos elaborados con base en datos de los Censos Generales de Población. 
Cuadro 2

ZONA DE INFLUENCIA DEL INGENIO EMILIANO ZAPATA:

DistribuCión DE LA POBLACIÓN E INCREMENTOS MEDIOS ANUALES POR MUNICIPIO, 1921-1970

\begin{tabular}{|c|c|c|c|c|c|c|c|c|}
\hline Munioipios & \multicolumn{3}{|c|}{ Numero de habitantes } & \multicolumn{3}{|c|}{ Poreleritos } & \multicolumn{2}{|c|}{$\begin{array}{l}\text { Inoremento } \\
\text { medio anual }\end{array}$} \\
\hline & & & & & & & & $1970^{\circ}$ \\
\hline Total do la zona & 48.939 & 83378 & 261565 & 100.00 & 100.00 & 100.00 & 2.74 & $3.50^{\circ}$ \\
\hline 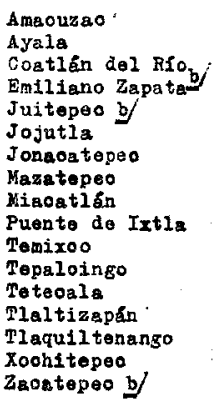 & $\begin{array}{ll}1 & 702 \\
4 & 161 \\
1 & 696 \\
& 663 \\
1 & 961 \\
5 & 173 \\
3 & 727 \\
1 & 113 \\
4 & 388 \\
4 & 707 \\
1 & 039 \\
5 & 253 \\
2 & 178 \\
3 & 390 \\
2 & 967 \\
3 & 694 \\
1 & 133\end{array}$ & $\begin{array}{ll}2 & 504 \\
8 & 528 \\
3 & 159 \\
3 & 168 \\
2 & 353 \\
9 & 200 \\
3 & 814 \\
2 & 239 \\
6 & 393 \\
8 & 580 \\
3 . & 420 \\
6 & 287 \\
2 & 756 \\
7 & 674 \\
5 & 685 \\
4 & 354 \\
3 & 254\end{array}$ & $\begin{array}{rl}6 & 748 \\
28 & 100 \\
7 & 727 \\
10 & 670 \\
19 & 567 \\
32 & 213 \\
7 & 379 \\
4 & 797 \\
11 & 740 . \\
24 & 189 \\
19 & 048 \\
13 & 211 \\
4 & 514 \\
19 & 695 \\
17 & 130 \\
11 & 425 \\
23 & 412\end{array}$ & $\begin{array}{r}3.48 \\
8.50 \\
3.47 \\
1.35 \\
4.01 \\
10.47 \\
7.61 \\
2.27 \\
8.97 \\
9.61 \\
2.12 \\
10.73 \\
4.45 \\
6.93 \\
6.06 \\
7.55 \\
2.32\end{array}$ & $\begin{array}{r}3.00 \\
10.23 \\
3.79 \\
3.80 \\
2.82 \\
11.03 \\
4.57 \\
2.69 \\
7.67 \\
10.29 \\
4.10 \\
7.54 \\
3.31 \\
9.20 \\
6.82 \\
5.23 \\
3.91\end{array}$ & $\begin{array}{r}2.58 \\
10.74 \\
2.95 \\
4.08 \\
7.48 \\
12.32 \\
2.82 \\
1.83 \\
4.49 \\
9.25 \\
7.28 \\
5.05 \\
1.73 \\
7.53 \\
6.55 \\
4.37 \\
8.95\end{array}$ & $\begin{array}{l}2.01 \\
3.61 \\
3.17 \\
6.88 \\
0.96 \\
2.95 \\
0.12 \\
3.56 \\
1.96 \\
3.07 \\
5.62 \\
0.94 \\
1.23 \\
4.08 \\
3.30 \\
0.88 \\
5.09\end{array}$ & $\begin{array}{l}3.11 \\
3.62 \\
2.84 \\
3.68 \\
5.32 \\
3.77 \\
2.16 \\
2.46 \\
2.00 \\
3.23 \\
4.72 \\
2.41 \\
1.64 \\
2.98 \\
3.40 \\
3.03 \\
5.12\end{array}$ \\
\hline
\end{tabular}

Fuente: Cálculos elaborados con base en datos de los Censos Generales de Población.

a Este incremento anual se calculó mediante la expresión: $I M A=2\left(P_{1}-P_{0}\right) /\left(P_{1}+P_{0}\right)(-)$ 100. En donde $P_{0}$ y $P_{1}$ son las poblaciones al principio y final del período, y $n$ el número de años.

b No tenían la categoría de municipio en 1921. Véase la nota 14.

aquellos donde se localizaban los pueblos principales -Jojutla, Puente de Ixtla y Tepalcingo - son los que presentan una mayor participación de población en la región en 1921 (véase Womack, op. cit. p. 385 y cuadro 2).

En este año - 1921 - las principales localidades de la región se distribuyen de manera dispersa localizándose principalmente en los municipios mencionados arriba (véase el mapa 2). Esta dispersión puede atribuirse a la manera en que se realizaba la producción de azúcar en época de los hacendados: un gran número de ingenios procesaban la caña de las haciendas, ya que la capacidad por unidad de los ingenios no alcanzaba a procesar la caña a más de tres o cuatro haciendas.

La dotación de ejidos en Morelos adquiere fuerza como resultado de la Ley Evolutiva Agraria de 1922, y para fines del año siguiente 115 de los 150 pueblos de la entidad habían recibido tierra ejidal. Para 1927, en el estado sólo funcionan cuatro o cinco haciendas y alrededor de 16800 ejidatarios habían tomado posesión definitiva de más de 120000 hectáreas por dotación o restitución de tierras (Womack, op. cit., 368369). 
Mapa 2

ZoNa DE INFluencia DEL INGENio EMiliano Zapata.

DISTRIBUCIÓN DE POBLACIÓN POR TAMAÑo DE LOCALIDAD, 1921

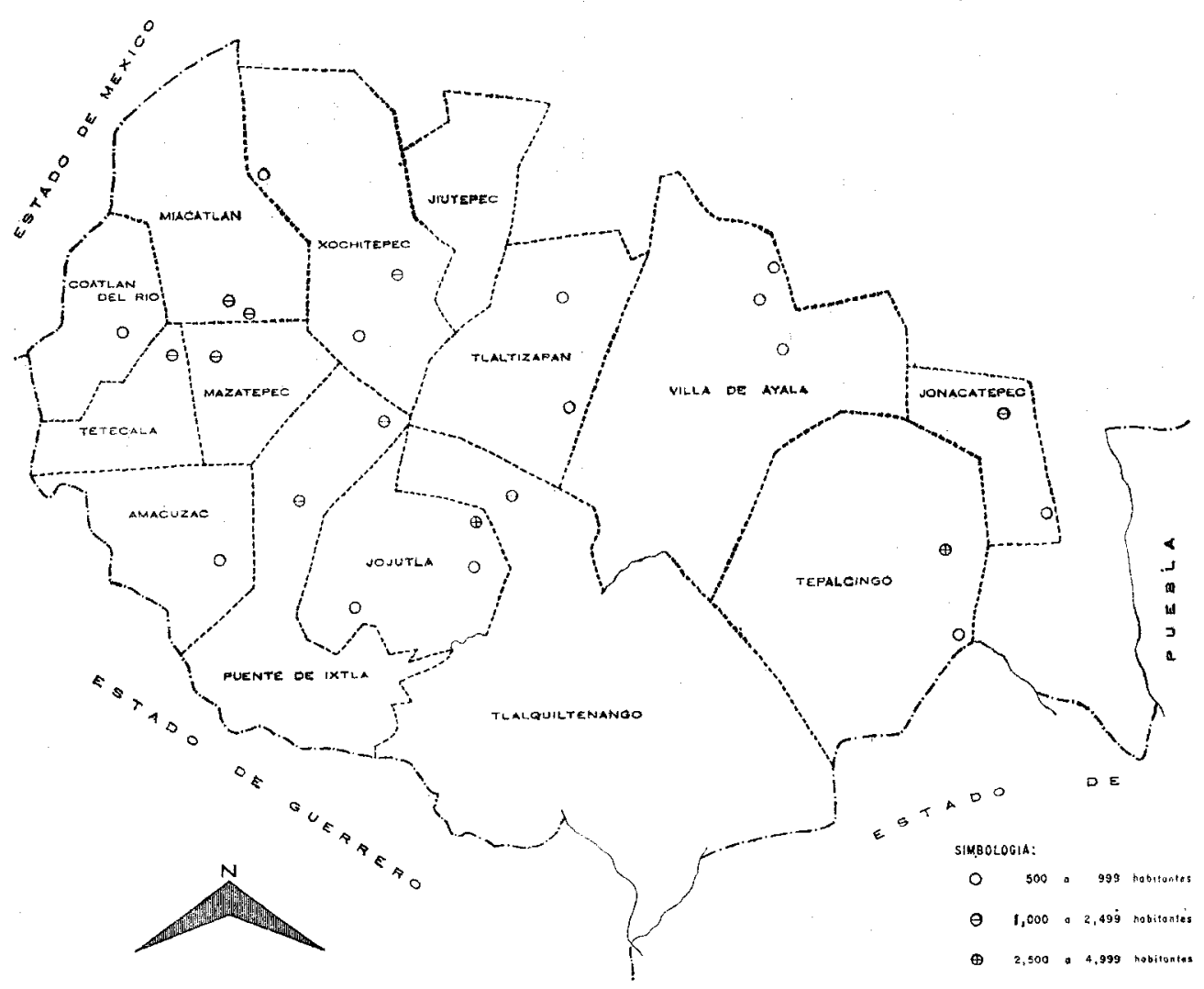


Esta política fue el factor primordial del poblamiento de la región hasta los años cuarenta: los habitantes de algunas localidades que habían desaparecido como consecuencia de la guerra de recolonización vuelven a la región a reclamar el derecho a sus pueblos; y habitantes no originarios de la región, frente a la perspectiva de la dotación de tierras crean nuevos centros de población. Este poblamiento se manifiesta más intensamente en el periodo cardenista; mientras en el periodo 1921-1930 aparecen 14 nuevas localidades, en el decenio 1931-1940 llega a 21 localidades (véase el cuadro 3 ).

\section{Cuadro 3}

ZONA DE INFLUENCIA DEL INGENIO EMILIANO ZAPATA: NÚMERo DE LOCALIDADES POR TAMAÑo, SEGÚN EL AÑo DE APARICIÓN, 1921-1970

\begin{tabular}{|c|c|c|c|c|c|c|c|}
\hline \multirow{2}{*}{$\begin{array}{l}\text { Año do } \\
\text { aparicion }\end{array}$} & \multicolumn{7}{|c|}{ I! úmero de localidades por tamaño (habitantes) } \\
\hline & Total & a 99 & a 499 & $=$ & a 999 & 2499 & a 4999 \\
\hline $1921 \mathrm{~b} /$ & 97 & 20 & 52 & & 13 & 10 & 2 \\
\hline 1930 & 14 & 7 & 6 & & 1 & - & 1 \\
\hline 1940 & 21 & 4 & 17 & & - & - & - \\
\hline 1950 & 11 & 3 & 7 & & 1 & - & - \\
\hline 1960 & 9 & 1 & 7 & & 1 & - & - \\
\hline 1970 & 33 & 14 & 12 & & 4 & 3 & - \\
\hline
\end{tabular}

Fuente: Cálculos elaborados con base en datos de los Censos Generales de Población.

a No se incluyen las localidades no especificadas.

b Ya existentes en ese año.

La expectativa de que la creación de nuevos centros de población se tradujera en dotación de tierras fue real. De las 14 localidades que aparecieron entre 1921 y 1930, 11 adquirieron el carácter de ejidos, y de las 21 que se crearon de 1931 a 1940, 15 obtuvieron esa categoría (Censos de Población y Directorio de Ejidos y Comunidades Agrarias, Dirección General de Estadística S.I.C.).

En 1938 se creó el ingenio Emiliano Zapata en el municipio de Zacatepec - que hasta entonces pertenecía a Tlaquiltenango - y comenzaron a generarse nuevas pautas en la distribución de población de la región. La superposición de estas nuevas pautas, apenas incipientes sobre las antiguas - que comienzan a desaparecer- se manifiesta ya, aunque de manera muy tenue, en el año de 1940. En este año existían 145 localidades y ninguna de ellas alcanzaba los 5000 habitantes. Tepalcingo y Jojutla, las localidades mayores en 1921, no crecieron sustancialmente en el periodo 1921-1940. Jojutla, a pesar de que ocupa el primer lugar en la región en 1940, en ese periodo sólo experimentó una tasa de crecimiento del $2 \%$ anual, y Tepalcingo incluso perdió población en términos absolutos en ese periodo (véase el cuadro 4). Es decir, el pobla- 
ZONA DE INFLUENCIA DEL INGENIO EMILIANO ZAPATA.

DISTRIBUCIÓN DE POBLACIÓN POR TAMAÑo DE LOCALIDAD, 1940

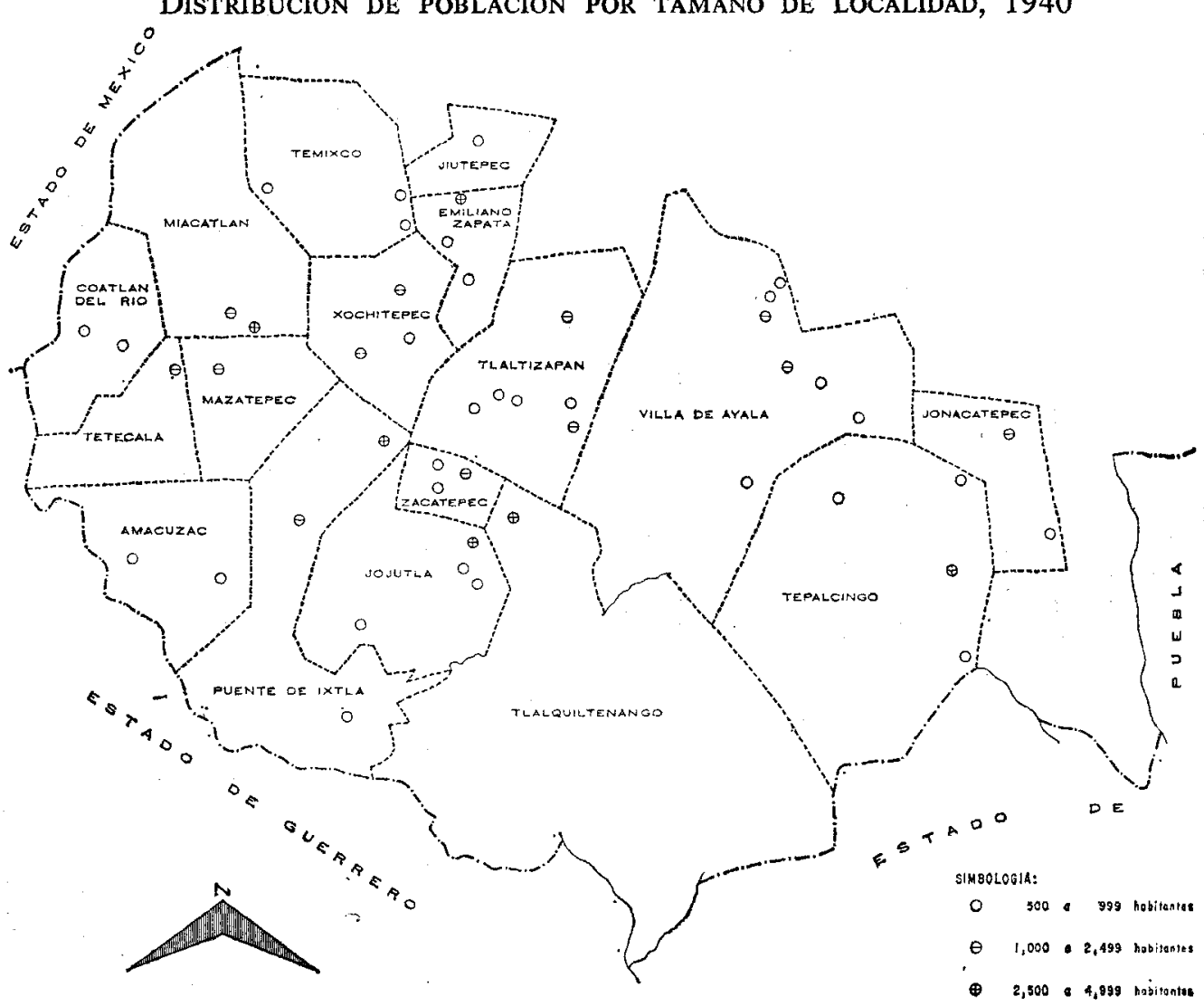


Zona de influencia del ingenio Emiliano Zapata: Evolucl

\begin{tabular}{|c|c|c|c|c|}
\hline \multirow[b]{2}{*}{ Rango } & \multicolumn{2}{|r|}{1921} & \multirow[b]{2}{*}{$\begin{array}{l}\text { Námero de } \\
\text { habitantes }\end{array}$} & \multirow[b]{2}{*}{ Localidades } \\
\hline & Iocalidades. & Municipios & & \\
\hline 1 & Tepalcingo & (Tepalcingo) & 3250 & Jojutza \\
\hline 2 & Jojutla & (Jojutla) & 2 & oxocotla \\
\hline 3 & Jonacatepec & (Jonacatepec) & 2190 & epalcingo \\
\hline 4 & Xoxocotia & (Puente de Ixtla) & $1996^{\prime}$ & Coạtetelco \\
\hline 5 & Puente de Ixtla & (Puente de Ixtla) & 1916 & laquiltena \\
\hline 6 & Tlaquiltenango & (Tlàquiltenaingo) & 1 & Puente de I \\
\hline .7 & Tetecala & (Tetecala) & 1606 & Miacatlán \\
\hline 8 & Coatetelco & (Miącatlán) & 15 & onacatepec \\
\hline 9 & Miacatlán & (Miacatlán ) & $1529^{\prime}$ & +Taltizapár \\
\hline 10 & Palpan & (Miacatlán) & 125 & Teteciala \\
\hline 11 & Mazatepec & (Mazatepec) & 1113 & +E. Zapata \\
\hline 32 & Xochitepec, & (Xochitepec) & 1103 & Xochitepec. \\
\hline
\end{tabular}

Fuente: Censos Generales de Población.

miento que se produjo en la región de 1921 a 1940, así como el lento crecimiento de las principales localidades existentes al principio del periodo, resultó -en 1940 - en una región eminentemente rural, densamente poblada y con un alto grado de dispersión (véase el mapa 3 ).

La pauta de distribución de población en 1940 es sólo la transición entre la antigua de 1921 (que semejaba la de la época de los hacendados) y uno nuevo, que centralizaría el procesamiento de la caña alrededor de un ingenio con una amplia escala de producción.

Ahora bien, como para este año - 1940 - las principales localidades del principio del periodo no habían perdido toda su importancia, y las que habrían de tenerla en el futuro no la habían ganado aún, la pauta de distribución es sumamente dispersa.

La presencia inminente de la nueva distribución de población puede derivarse de las distintas tasas de crecimiento de la población muncipal de 1921 a 1940 (véase el cuadro 2). Las diferencias entre las tasas de los municipios son muy marcadas; mientras que Jonacatepec y Tepalcingo no alcanzaban el $1 \%$ anual, los municipios de nueva creación Em: 
RANGO DE LAS LOCALIDADES PRINCIPALES, 1921-1970

\begin{tabular}{|c|c|c|c|c|}
\hline & & & 1970 & . \\
\hline ipios & $\begin{array}{l}\text { Numero de } \\
\text { habitantes }\end{array}$ & Localidades & Municipios & $\begin{array}{l}\text { Número de } \\
\text { habitantes }\end{array}$ \\
\hline tla) & 4.481 & tzacatepec & (Zacatepec) & 16839 \\
\hline te de Ixt1a) & 3081 & Jojutla & (Jojutla) & 14438 \\
\hline leingo) & 3076 & Puente de Ixtla & (Puente de Ixtia) & 10435 \\
\hline atlán) & 2857 & +Terixco & (Temixco) & 8979 \\
\hline (ailtenango) & 2518 & Tlaquil tenango & (Tlaquil tenango) & 8625 \\
\hline te de $T x t l a)$ & $2470^{\prime}$ & +icatilipa & (Temixco) & 7033 \\
\hline ztıán) & 2439 & $X_{\text {XoxocotIa }}$ & (Puente de Ixtla) & 6426 \\
\hline extepec) & 252 & Tlaltizapán & (Tlaltizapán) & 6384 \\
\hline tizapán) & 1966 & E. Zapata & (E. Zavata) & 6250 \\
\hline $2 a(a)$ & 1892 & Tepalcingo & (Tepalcingo) & 5968 \\
\hline pata) & $1630^{\prime}$ & Coatetelco & (Miacatlán) & 5268 \\
\hline (tepec) & 15327 & +Juitepec & (Juitepec) & 4478 \\
\hline
\end{tabular}

liano Zapata, Temixco y Zacatepec ${ }^{1 \cdot 1}$ experimentaron tasas mayores de $5 \%$. En menor medida se presentan diferencias entre municipios como Tlaltizapan y Ayala — que llegarán a ser de los más importantes en la zona cañera- con tasas de crecimiento mayores al $3.5 \%$ anual, respecto de municipios como Miacatlán y Tetecala con tasas menores al $2 \%$, los que sólo llegarán a tener una participación marginal en la producción de caña en la región.

El poblamiento originado por el reparto de tierras (1921-1940) permitió que el cultivo de la caña volviese a la región; el cultivo se implantó en base a tierra ejidal una vez inaugurado el ingenio Emiliano Zapata,

14 El municipio Emiliano Zapata se creó en 1932 con localidades del municipio de Jintepec; Temixco se creó en 1933 con localidades de los municipios de Xochitepec y Cuernavaca, y Zacatepec se creó en 1938 con localidades del municipio de Tlaquiltenango. (Censos de Población y División Municipal de las Entidades Federativas, Dirección General de Estadística, SIC). Hay discrepancia entre estas fuentes en relación al municipio de Temixco, la segunda fuente dice que este municipio se creó con localidades de Emiliano Zapata, Jiutepec y Xochitepec, pero en el Censo sólo se pueden derivar localidades de Xochitepec y Cuernavaca. En el cuadro 2, con el objeto de poder comparar su dinámica poblacional, se han tratado estos tres municipios como si hubieran existido desde 1921. 
el que, desde su origen (1938), tuvo un impacto decisivo en la actividad económica de la región. ${ }^{15}$

Las características que tomará el proceso productivo en la región con el cultivo de la caña dará una nueva modalidad al poblamiento de la región. En el periodo 1940-1970 disminuye de manera considerable el reparto de tierras, por lo que aparecen menos localidades que en el periodo 1921-1940; sin embargo, el crecimiento de la población de la región no disminuye, sino que se da con mayor intensidad. En 1970, la población de la zona de estudio alcanza 261565 habitantes, tres veces más que la población de 1940 . La tasa de crecimiento de la población de la región en el periodo 1940-1970 fue de 3.5\% anual, mientras que, en el periodo 1921-1940, sólo alcanzó el 2,7\% (véase el cuadro 2).

Este crecimiento de población se explica menos por la aparición de nuevas localidades, que por el crecimiento acelerado de algunas de ellas. En el periodo 1940-1960 aparecieron 20 localidades (once de 1940 a 1950 y nueve 1950 a 1960), 15 menos que entre 1921-1940, y de éstas sólo seis adquirieron la categoría de ejido ${ }^{16}$ (Censos de Población y $\mathrm{Di}^{-}$ rectorio de Ejidos y Comunidades Agrarias). Por otra parte, mientras en 1940 no existían localidades mayores de 5000 habitantes, en 1970 se presentan ocho localidades entre 5000 y 9999 habitantes y tres entre 10000 y 20000 (véase el cuadro 1). Es decir, de 1940 a 1970 una norma de distribución eminentemente rural es sustituida por otra de carácter semiurbano (véanse los mapas 3 y 4).

Dos han sido los factores determinantes para este cambio en la distribución de población: la creación del ingenio Emiliano Zapata y el proceso de metropolización de la ciudad de Cuernavaca.

La creación del ingenio en Zacatepec dio lugar a un crecimiento desorbitado de esa localidad (de 1940 a 1970 pasó de 1917 habitantes a $16839)$ y al crecimiento sostenido de las localidades más cercanas, Jojutla y Tlaquiltenango, que pudieron mantener su importancia desde 1921 (véase el cuadro 4). Alrededor de estas tres ciudades se distribuyen un gran número de núcleos de población cuya importancia está asociada con el grado de participación en el abasto de caña de azúcar al ingenio.

A nivel municipal, este proceso de redistribución de población puede observarse en el cuadro 2. La participación que tuvieron en 1921 municipios como Miacatlán, Tetecala y Jonacatepec disminuye sustancialmente, mientras que los principales municipios cañeros - Ayala, Puente de Ixtla, Tlaltizapán - mantienen la participación que gardaban al principio del periodo de estudio.

15 A tres años de su creación 47 ejidos abastecían con caña al ingenio E. Zapata. Véase, M. H. Barreda, op. cit.

16 De 1960 a 1970 aparecieron 33 localidades (véase el cuadro 3). Al considerar que el Censo de Población de 1970, a diferencia de los anteriores, se realizó en época de zafra, es posible suponer que la mayor parte de esas localidades sean de corta duración. Por otra parte, estas localidades sólo alcanzan 10888 habitantes, cifra menor al $5 \%$ de la población total de la región en 1970 . 
ZONA DE INFLUENCIA DEL INGENIO EMILIANO ZAPATA.
DisTRIBUCIÓN DE POBLACIÓN POR TAMAÑo DE LOCALIDAD, 1970

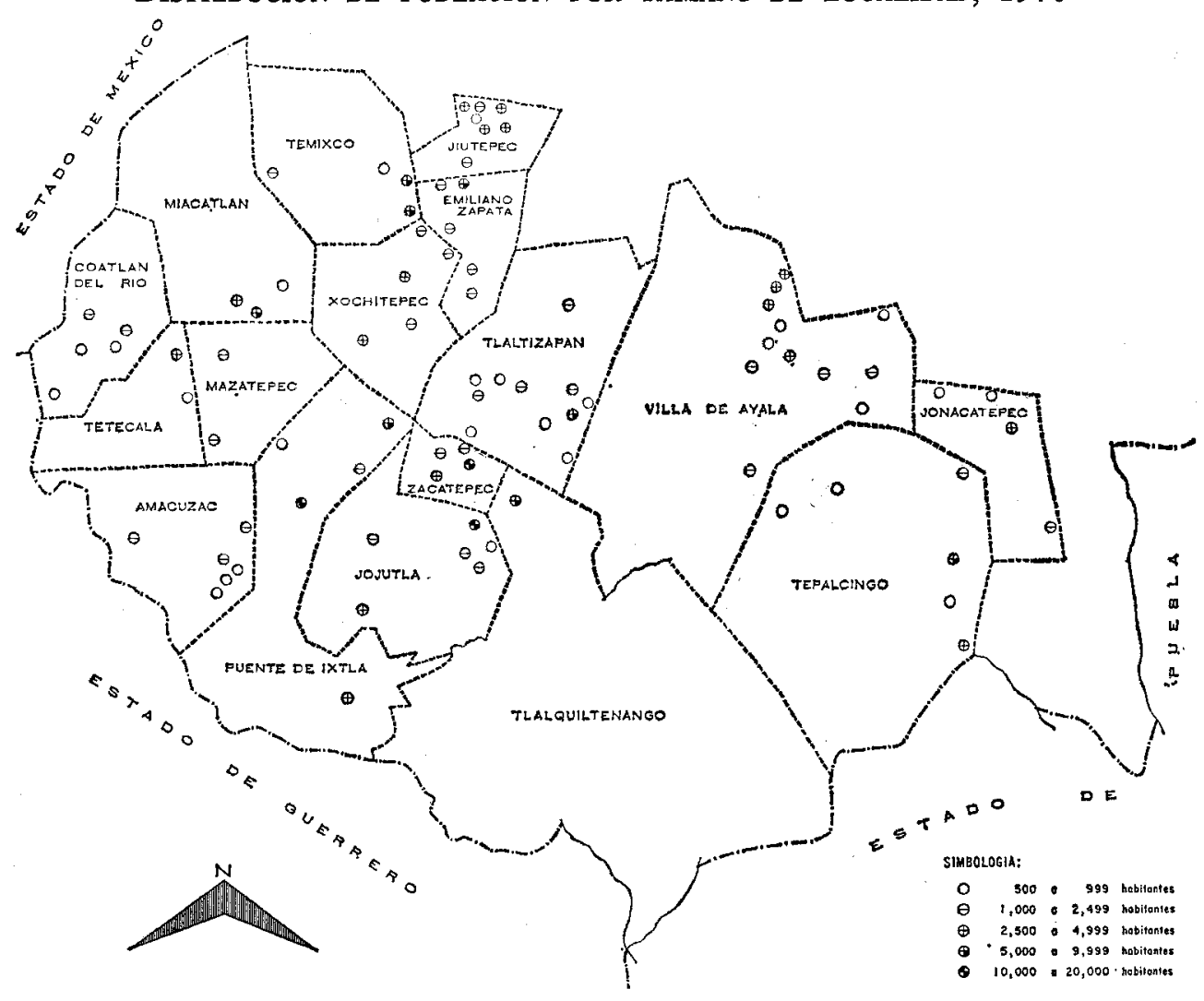


Por otra parte, en un proceso completamente diferente, el crecimiento de la ciudad de Cuernavaca da lugar a que municipios como Emiliano Zapata, Jiutepec y Temixco eleven su participación en la población de la zona en una forma considerable, y que cuatro de las localidades de estos municipios se encuentren entre los principales de la región en $1970^{17}$ (véanse los cuadros 2 y 4 ).

$\mathrm{El}$ análisis del cambio en la distribución de población en esta región, en el periodo 1921-1970 indica la inestabilidad que puede tener a mediano plazo cualquier norma de distribución rural. Esta inestabilidad -al menos en el corto plazo- parece depender de los determinantes - primordialmente económicos- del crecimiento de población de los distintos tamaños de localidades.

\section{Estructura productiva y crecimiento de la población}

La organización de la industria azucarera en México tiene un carácter esencialmente gubernamental. A pesar de que el sector público no participa exclusivamente en ella, su desarrollo en los últimos decenios ha seguido las pautas de un gran número de empresas paraestatales: un comportamiento económico irracional (estructura de ingresos menor que la de sus costos) que sólo se ha sostenido por el apoyo financiero del Estado. ${ }^{15}$

En años recientes, en especial al final del sexenio 1970-1976, la participación del sector público en la industria despertó un interés particular por dos razones: en los últimos años de ese sexenio, la importancia del azúcar en la balanza comercial disminuyó de manera considerable: un aumento (más que proporcional) en el consumo interno (respecto al incremento en la producción) ha generado una baja notable en el nivel de exportaciones. También en ese periodo - primero en 1970 y luego en 1975- se planteó la reestructuración de la organización de la industria, para abatir su ineficiencia económica. Se resumen a continuación los antecedentes de estas alteraciones.

En el decenio del sesenta (con la cancelación de la cuota que tenía Cuba en el mercado de azúcar norteamericano) se acentuó la importancia de este producto en la balanza comercial; mientras en 1959 se exportaron 61000 toneladas de azúcar a ese mercado, en 1960 esta cifra aumentó a 354000 toneladas. Esta cantidad crece y se mantiene alrededor de las 500000 toneladas hasta 1975 , cuando se presenta un decremento brusco en las exportaciones. ${ }^{19}$ En los últimos años, el aparato productivo

17 En este trabajo no he analizado la dinámica poblacional de estos municipios desde el punto de vista del proceso de metropolización de la ciudad de Cuernavaca, se estudian conforme la relación estructura agraria-crecimiento de población.

18 Véase S. Maturana e I. Restrepo, El azúcar: problema de México. Un estudio regional en Michoacán, México, Centro de Investigaciines Agrarias, 1970.

19 Véase R. Lajous, La participación de México en el mercado azucarero norteamericano (tesis de licenciatura, El Colegio de México, CEI, 1975). 
de la industria no ha sido capaz de responder al crecimiento del consumo interno, lo que ha provocado una disminuición de las exportaciones (hasta el punto que se presenta el peligro de que México pueda convertise en importador de azúcar)..$^{20}$

En lo que hace a la organización de la industria, diferentes controles gubernamentales han acompañado al proceso productivo. Esos controles se ejercen desde el cultivo de la caña hasta la producción y venta del azúcar. $^{21}$

Con el propósito de asegurar el cultivo de la caña, se han establecido por decreto "zonas de abastecimiento" para los ingenios, que deben dedicarse en exclusiva al cultivo de ese producto. ${ }^{22}$ Los campesinos de estas zonas, primordialmente ejidatarios, no pueden dedicar su parcela a otros cultivos; esta restricción ha sido motivo de conflictos, ya que la caña no significa una ventaja para su_cultivador.

El control sobre los obreros de los ingenios ha sido muy diferente del que se ejerce sobre los cañeros. Los obreros han sabido ejercer una presión sustancial en la industria, lo que se ha reflejado en salarios altos y en niveles de sobreempleo y, en consecuencia, en elevados costos de producción.

La administración del crédito y la comercialización del azúcar se había realizado a través de la UNPASA (Unión Nacional de Productores de Azúcar, S. A.) ${ }^{2.3}$ La Unión con la representación de todos los ingenios se encargaba, por una parte, del financiamiento de los gastos agrícolas e industriales de la producción $\mathrm{y}$, por otra, comercializaba la producción nacional de azúcar.

El crédito para gastos agrícolas e industriales se hacía a través del ingenio, que administraba el crédito para la siembra y cultivo de la caña, haciéndose responsable frente a UNPASA y acreedor frente al cañero (este papel de intermediarios por parte del ingenio se encontraba vigente en la

20 Véase Excélsior, México, 9 de junio de 1977.

21 Un buen estudio sobre el marco institucional de esta industria es el artículo de Samuel del Villar, "Depresión en la industria azucarera mexicana", Foro Internacional, Vol. XVI, abril-junio de 1976, pp. 526-585.

22 En septiembre de 1943 se facultó a la Secretaría de Agricultura y Fomento (como se llamaba en esa época) para fijar zonas de abastecimiento de caña de azúcar para cada ingenio. En 1975 se abrogó el decreto de 1943, y la fijación de zonas pasó a tener el carácter de resolución presidencial (ibid., pp. $538-539$ y 567-568).

23 De 1940 a 1970 , UNPASA, con el apoyo de FINASA (Financiera Nacional Azucarera, S. A.), se había encargado del crédito y la comercialización del azúcar en el país. En 1970, con el fin de centralizar la administración gubernamental en la industria, se crea la CNIA (Comisión Nacional de la Industria Azucarera) como un organismo federal descentralizado facultado para coordinar la política azucarera así como para administrar los ingenios del Estado. A la CNIA quedaron integrados los organismos antes mencionados -UNPASA y FINASA-, y uno de nueva creación, oNISA (Operadora Nacional de Ingenios). En 1975 se hace una nueva restructuración en la industria para apoyar la realizada en 1970. Estos cambios han acarreado un buen número de problemas sin que se conozca aún la posible eficiencia que la restructuración traerá a la industria (ibid., pp. 545-585). He dejado de lado esta discusión con el objeto de presentar las características de la industria en la forma más simple. 
zona de estudio en el momento de esta investigación, julio-septiembre de 1976). El crédito que el ingenio da al cañero es otro mecanismo de control, ya que la deuda constante del cañero con el ingenio asegura que se dedique al cultivo de la caña.

Por último, la comercialización del azúcar se ha realizado con una política de control y subsidio de precios, ${ }^{24}$ lo que ha impedido -debido a los elevados costos de producción - que la industria tenga capacidad de autofinanciamiento y haya abierto la posibilidad para que el sector gubernamental aumente su participación en ella.

La región que estudio se encuentra dentro de ese marco institucional, es decir, se trata de una zona de abastecimiento (o de influencia') en donde el ingenio vigila el cultivo y el corte de caña mediante el control sobre los cañeros y cortadores.

a) Zona de influencia del ingenio Emiliano Zapata: Sociedades Ejidales y Ejidos no Sociedades. Las principales zonas cañeras de México se encuentran en las entidades de Veracruz, Jalisco, Sinaloa, Tamaulipas, Morelos, Oaxaca y Michoacán. En el año de 1974, en estas seis entidades se localizaban 50 de los 65 ingenios productores de azúcar en el país, entre los cuales destacaban San Cristóbal y El Potrero en Veracruz, Emiliano Zapata en Morelos, Los Mochis en Sinaloa y El Mante en Tamaulipas. ${ }^{25}$

El ingenio E. Zapata ha funcionado desde 1938 con el carácter de sociedad cooperativa, de la que son miembros ejidatarios, pequeños propietarios, obreros y empleados del ingenio. Cada ejido que aporta caña al ingenio tiene el carácter de "sociedad" en la cooperativa. Sesenta y tres sociedades forman la zona de estudio; 8500 cañeros cultivan allí alrededor de 20000 hectáreas. La mayoría de los cañeros son ejidatarios $(90 \%)$, y como no existen diferencias sustanciales entre los tamaños de parcela de ejidatarios y pequeños propietarios, la mayor parte de la tierra cultivada es ejidal (un $80 \%$ ). ${ }^{26}$

En la zona de influencia del ingenio, la caña se cultiva en terrenos de riego, y como las aguas que se utilizan para el cultivo provienen principalmente de ríos y manantiales de carácter permanente, la localización de los núcleos de población cañeros (sociedades) está restringida por los rẹcursos hidrológicos de la región. ${ }^{27}$ Como estos recursos no se distribu-

24 El precio del azúcar para el consumo interno ha estado constantemente por debajo del precio en el mercado mundial. La política de congelamiento de precios ha sido en gran parte la causa de este fenómeno (ibid., pp. 555-567).

${ }_{25}$ Manual azucarero mexicano 1975, 18a. edición, Compañía Editorial Manual Azucarero, S. A., Mexico, 1975.

${ }_{26}$ El tamaño medio de parcela ejidal es aproximadamente de dos hectáreas; el de los cañeros particulares es de cinco hectáreas; véase Ingenio Emiliano Zapata. Listado por sociedad (superficies y cultivos de la zona de abasto), abril de 1976.

${ }_{27}$ H. W. Richardson ha definido estos determinantes locacionales como "constantes locacionales", Regional Growth Theory, London, The Mac Millan Press, 1974, pp. 172-175. En este trabajo no he hecho referencia específica a las características geográficas de las zonas, a pesar de su importancia, porque no conozco bien esa especialidad. 
yen en forma homogénea, diferentes tipos de localidades - cañeras y no cañeras - se encuentran dentro de la región.

En 1970, la población de los 17 municipios que comprende la zona de influencia estaba distribuida en 185 localidades. De éstas 112 son ejidos, 63 son sociedades ejidales y 59 tienen carácter ejidal sin ser sociedades, el resto (63) no tienen carácter ejidal (véase cuadro 5). Con excepción de Emiliano Zapata, Mazatepec, Xochitepec y Zacatepec, los municipios tienen los tres tipos de localidades, aunque en diferente proporción. Los municipios con mayor número de sociedades son Ayala, Tlaltizapán, Jojutla y Xochitepec; Tlaquiltenango y Tepalcingo son los de mayor número de ejidos no sociedades (véase cuadro 5).

\section{Cuadro 5}

ZONA DE INFLUENCIA DEL INGENIO EMILIANO ZaPATA: NÚMERO DE SOCIEDADES EJIDALES, EJIDOS NO SOCIEDADES Y LOCALIDADES NO EJIDALES POR MUNICIPIO (1970-1976)

\begin{tabular}{|c|c|c|c|c|}
\hline Muniolpios & $\begin{array}{c}\text { Total do } \\
\text { localidados }\end{array}$ & $\begin{array}{l}\text { Sociedados } \\
\text { ejidalos }\end{array}$ & $\begin{array}{l}\text { Ejidos no } \\
\text { sociedadea }\end{array}$ & $\begin{array}{l}\text { Loealidader } \\
\text { no ojidales }\end{array}$ \\
\hline Total de la region & 185 & 63 & 59 & 63 \\
\hline 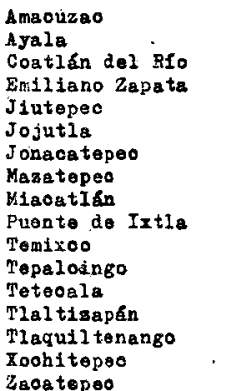 & $\begin{array}{r}9 \\
28 \\
10 \\
5 \\
12 \\
14 \\
7 \\
3 \\
12 \\
10 \\
8 \\
11 \\
5 \\
16 \\
22 \\
9 \\
4 .\end{array}$ & $\begin{array}{r}2 \\
10 \\
1 \\
4 \\
3 \\
7 \\
2 \\
2 \\
2 \\
3 \\
2 \\
3 \\
2 \\
10 \\
1 \\
6 \\
3\end{array}$ & $\begin{array}{l}2 \\
7 \\
4 \\
- \\
2 \\
2 \\
2 \\
1 \\
3 \\
4 \\
3 \\
7 \\
1 \\
4 \\
17 \\
- \\
-\end{array}$ & $\begin{array}{r}5 \\
11 \\
5 \\
1 \\
7 \\
5 \\
3 \\
\\
7 \\
3 \\
3 \\
1 \\
2 \\
2 \\
4 \\
3 \\
1\end{array}$ \\
\hline
\end{tabular}

FunNTE: Censo de Población, 1970, Directorio de Ejidos y de Comunidades Agrarias ( $V$ Censo Ejidal, 1970) e Ingenio Emiliano Zapata, Listado por Sociedades de Superficie y Cultivos de la Zona de Abasto, abril de 1976.

a Las sociedades ejidales abastecen de caña al ingenio mientras los ejidos no sociedades se dedican a otros cultivos.

Las sociedades (ejidos cañeros') se dedican principalmente a cultivos de riego: la caña y el arroz (este último se realiza de manera primordial en forma de rotación: sembrada la plantilla y hechos los cortes de ésta más el de dos o tres socas, se cultiva el arroz para mejorar el terreno). En los ejidos que no tienen el carácter de sociedad, los cultivos son de temporal: maíz, frijol, cacahuate, etc. El predominio de sociedades ejidales o de ejidos no sociedades en los distintos municipios, ayuda a comprender el patrón de cultivos a nivel municipal, el nivel más desagregado para el que existe este tipo de información (véase el cuadro 6). 
Cuadro 6

ZONA DE INFLUENCIA DEL INGENIO EMILIANO ZAPATA: SUPERFICIE COSECHADA DE LOS PRINCIPALES CULTIVOS POR MUNICIPIO, 1970

(porcientos) $^{\mathrm{a}}$

\begin{tabular}{|c|c|c|c|c|c|c|c|}
\hline Huniolpios & $\begin{array}{l}\text { Total do } \\
\text { heotáross }\end{array}$ & Arroz & $\begin{array}{l}\text { Caca- } \\
\text { huate }\end{array}$ & $\begin{array}{l}\text { Caña do } \\
\text { azúcar }\end{array}$ & Frijol & $\mathrm{MaIz}$ & Otros \\
\hline Total do la $\operatorname{seg} 18 n$ & $\begin{array}{lll}46 & 072.7\end{array}$ & 9.94 & 4.38 & 25.92 & 4.72 & 49.93 & 5.11 \\
\hline  & $\begin{array}{ll}1 & 380.8 \\
8 & 084.2 \\
1 & 724.3 \\
2 & 121.2 \\
1 & 094.9 \\
2 & 978.6 \\
1 & 682.7 \\
1 & 412.4 \\
3 & 964.5 \\
3 & 385.8 \\
1 & 870.1 . \\
3 & 738.5 \\
1 & 139.4 \\
5 & 495.7 \\
3 & 981.4 \\
1 & 966.3 \\
1 & 059.8\end{array}$ & $\begin{array}{r}2.86 \\
6.22 \\
7.67 \\
37.59 \\
45.17 \\
10.00 \\
5.83 \\
15.03 \\
2.03 \\
1.34 \\
24.74 \\
6.21 \\
12.52 \\
6.45 \\
11.39 \\
16.26 \\
15.30\end{array}$ & $\begin{array}{r}8.29 \\
0.27 \\
28.59 \\
0.19 \\
0.01 \\
1.90 \\
0.79 \\
10.94 \\
13.87 \\
5.33 \\
0.46 \\
0.19 \\
5.37 \\
4.80 \\
0.14 \\
2.56 \\
3.76\end{array}$ & $\begin{array}{r}12.54 \\
31.48 \\
12.40 \\
23.58 \\
3.82 \\
33.57 \\
3.12 \\
20.71 \\
13.21 \\
27.75 \\
22.42 \\
0.92 \\
1.83 \\
51.84 \\
33.24 \\
35.72 \\
50.50\end{array}$ & $\begin{array}{r}1.99 \\
13.56 \\
6.47 \\
4.26 \\
6.39 \\
1.07 \\
1.44 \\
0.77 \\
0.32 \\
0.08 \\
6.00 \\
1.96 \\
18.44 \\
2.92 \\
1.10 \\
5.17 \\
3.22\end{array}$ & $\begin{array}{l}74.18 \\
43.27 \\
42.50 \\
29.13 \\
40.46 \\
40.48 \\
85.11 \\
52.35 \\
68.01 \\
63.57 \\
45.51 \\
88.45 \\
60.68 \\
22.18 \\
48.57 \\
32.46 \\
25.37\end{array}$ & $\begin{array}{r}0.12 \\
5.20 \\
2.37 \\
5.25 \\
4.12 \\
12.62 \\
3.71 \\
0.20 \\
1.96 \\
1.93 \\
0.86 \\
2.27 \\
1.16 \\
11.86 \\
5.56 \\
7.83 \\
1.85\end{array}$ \\
\hline
\end{tabular}

FuENTE: Censo Agrícola. Ganadero y Ejidal, 1970.

a La suma de los porcientos de los principales cultivos para cada municipio es igual al 100 por ciento.

Al compararse los cuadros 5 y 6 puede observarse que los cultivos de riego predominan en los municipios de mayor número de sociedades: el arroz en Emiliano Zapata, Juitepec y Temixco, y la caña en Xochitepec, Tlaltizapan, Zacatepec, Jojutla y Ayala; mientras que en los cultivos de temporal destacan los municipios de mayor número de ejidos no constituidos en sociedades: el maíz en Jonacatepec, Tepalcingo y Tetecala. El cultivo del maíz y el del cacahuate en Coatlán del Río, Miacatlán y Amacuzac. En otros municipios como en los casos de Puente de Ixtla y Mazatepec esta distinción no es clara. Por último, el municipio de Tlaquiltenango con una sola sociedad presenta una gran proporción de su superficie cosechada dedicada a la caña. Es decir, la zona predominantemente cañera se localiza en los municipios que rodean al de Zacatepec - centro de la región de estudio-; al norte, cerca de Cuernavaca, destacan los municipios arroceros, mientras en el este y oeste de la zona se ubican los municipios con cultivos de temporal (véase el mapa 1).

b) Organización del proceso productivo: posiciones en el trabajo. El marco institucional donde se desenvuelve el cañero de las sociedades ejidales es muy diferente al del ejidatario que no pertenece a esas sociedades. Para el primero la dependencia con el ingenio es total, de él recibe el crédito (avío o "refacción") para las distintas tareas laborales y a él 
vende su producto (la caña). El segundo recibe el crédito de fuentes oficiales o privadas (bancos gubernamentales o usura) y puede vender su producto al mercado gubernamental o al privado (CONASUPO o empresas particulares'). Mientras el primero tiene prestaciones de seguridad social y acceso a una infraestructura escolar que le permite educar a sus hijos, el segundo carece de esos servicios. Sin embargo, el nivel de ingresos no difiere sustancialmente porque el tamaño de parcela del ejidatario cañero como el del ejidatario no cañero alcanzan apenas para un ingreso familiar de subsistencia.

En años de malas cosechas, para el cañero existe la posibilidad de endeudarse con el ingenio, pero el segundo, por lo general, tendrá que recurrir a la usura. En ambos casos se recurre con frecuencia al arrendamiento de parte de la parcela, y personas allegadas al ingenio, o particulares, son comunmente los arrendadores. El ejidatario acostumbra arrendar su tierra por un año para no perder el derecho que tiene sobre su parcela, lo que no deja de ser contradictorio ya que el arrendamiento mismo tiene un carácter ilícito. ${ }^{28}$

La situación que guardan en la región los cultivadores particulares - cañeros y no cañeros - es difícil de detectar, ya que tanto los tamaños de parcela - por la práctica del arrendamiento- como los tipos de cultivo pueden cambiar de un año a otro. ${ }^{99}$ Sin embargo, es posible suponer que aunque su participación en la estructura económica de la zona sea relativamente importante, ésta no afecta en forma determinante su dinámica demográfica, porque ésta se asocia más directamente con el cultivo de la caña (la participación del sector privado en el valor de la producción agrícola de la zona, en 1970, alcanzó sólo el 20\%, Censo agrícola, ganadero y ejidal).

A los cañeros - principalmente ejidatarios-, y a los ejidatarios no cañeros habría que agregar "los jornaleros" para tener las tres posiciones en el trabajo sobre las que gira el proceso productivo de la región. ${ }^{.30}$

La forma en que se interrelacionan estos tres tipos de trabajadores puede explicarse al introducir el concepto de tiempo de producción y

28 La nueva Ley de Reforma Agraria (abril de 1971) estipula, en el artículo 52, que la propiedad de los núcleos de población ejidales "no podrán en ningún caso ni en forma alguna enajenarse, cederse, transmitirse, arrendarse, hipotecarse en todo o en parte"; y el artículo 85, fracción I, indica que el ejidatario perderá sus derechos sobre la unidad de dotación si "no trabaja la tierra personalmente o con sus familiares durante dos años consecutivos o más..."

:9y Algunos cañeros particulares dedican sólo parte de su tierra al cultivo de la caña, mientras utilizan el resto de la parcela para otros cultivos, aprovechando la accesibilidad a los servicios de riego. Otro fenómeno -quizás más importante- es el arrendamiento de grandes extensiones de tierra por particulares no cañeros, para el cultivo de algunos frutales, pero como este tipo de prácticas no se hace en forma sistemática es difícil conocer su magnitud.

30 Es difícil estimar la cantidad de trabajadores para estos tres tipos de posiciones en el trabajo. El Censo de Población de 1970 presenta definiciones aproximadas pero poco específicas, lo que impide una asociación clara entre las posiciones que aquí se presentan y las que define el Censo. Existen otras referencias a la población trabajadora en el cultivo de la caña (Informe UNPASA, 1970), pero no se hace mención de la población activa dedicada a otros cultivos. 
tiempo de trabajo: ${ }^{31}$ en la agricultura el tiempo de producción es diferente al tiempo de trabajo, no sólo porque el periodo entre la siembra y la cosecha no abarca todo el año (hay época de secas), sino porque durante el cuidado del cultivo las labores no son igualmente intensivas. Esta característica de las labores agrícolas ha sido utilizada para explicar tanto el trabajo artesanal de los campesinos, como la migración intra-rural o al sector urbano.

En la región de estudio, se presenta una gran diversificación en las pautas de cultivo, de tal manera que las actividades agrícolas están presentes en casi todas las épocas del año. Los cultivos de corta duración, arroz, frijol, tomate, requieren de mano de obra en épocas que no son, necesariamente, las de mayor intensidad en las labores de los cultivos de temporal; el corte de caña —zafra- se realiza en épocas de seca, por lo que, agregando los cultivos de temporal, podríamos decir que las actividades agrícolas de la región no se detienen durante todo el año.

La diversificación de cultivos podría emplear la mayoría de cañeros y ejidatarios mediante migración intra-rural, pero no ocurre así. El cañero ejidatario se dedica casi en exclusiva al cultivo de la caña y no se enrola como cortador en el tiempo de zafra. Como el cultivo de la caña antes del corte no requiere labores intensivas, y como el tamaño de su parcela apenas le permite un ingreso de subsistencia, el resultado es no sólo un constante endeudamiento con el ingenio, sino también un trato despectivo por su "falta de actividad". En el caso del ejidatario o cañero, la situación es semejante (aunque no padece el trato paternalista del ingenio, lo tiene, en menor medida, de las instituciones de crédito y comercialización oficiales o privadas); a pesar de su bajo nivel de ingreso generalmente no se emplea como cortador en época de zafra.

Esta situación —comprensible a nivel del ejidatario jefe de familiase hace más patente con el desarrollo del ciclo familiar. Como las familias campesinas tienen un número elevado de hijos, y como el tamaño de parcela difícilmente puede sostener a más de dos familias; la mayoría de los hijos de ejidatarios están obligados a emplearse como jornaleros. Sin embargo, como el corte de caña hecho por migrantes se tiene como un trabajo inferior, sólo se acepta el jornal cuando proviene de otros cultivos. Gran parte de esos hijos de ejidatarios, llegado el momento de unirse en matrimonio $\longrightarrow$ al llegar a la mayoría de edad- prefieren migrar a la ciudad que afrontar un futuro de jornalero de por vida. Es decir, la imposibilidad de reproducir las relaciones sociales del padre de familia (ejidatario) los hace decidirse por un cambio de relaciones distintas a las que se darían en el sector agrícola. El proceso de diferenciación social no ha sido independiente del crecimiento natural de la

31 Véase K. Marx, El capital, tomo 2, capítulo 13, México, Fondo de Cultura Económica, 1966, pp. 212-220. 
población, sino que éste ha sido uno de sus factores determinantes. ${ }^{82} \mathrm{Un}$ condicionante - pocas veces mencionado- de esa diferenciación ha sido la actitud frente al trabajo del migrante -cortadores-, por considerar que éste acepta labores de inferior calidad..33

Los requisitos de mano de obra para la zafra se cubren por trabajadores no originarios de la región. Cuando se acerca la zafra, enganchadores del ingenio — cabos de corte- se dirigen a las zonas más atrasadas de las entidades cercanas - Guerrero, Puebla, México, Oaxaca- para contratar cortadores. Los cortadores, por lo general, entran a la zona cuando comienza el corte y salen al terminar la zafra. Sin embargo, algunos de ellos han aprovechado las "ventajas" que ofrece la región al jornalero de tiempo completo para improvisar localidades sin acceso a tierras de labor o para engrosar la población de localidades existentes. Estos invasores de núcleos de población, dedicados a labores agrícolas, comienzan a considerarse problema para la región ${ }^{34}$

En síntesis, podemos decir que la persistencia de un campesino medio -ejidatario cañero o no cañero- es real, pero la imposibilidad de su reproducción con mayor amplitud - crecimiento natural de la población vs. escasez de tierras - ha dado lugar a un doble proceso de proletarización: uno que se produce fuera de la región por la emigración de hijos de ejidatarios al mercado laboral urbano, y otro, dentro de la región, donde una cantidad numerosa de inmigrantes procuran integrarse como jornaleros de por vida.

c) Crecimiento de población por tamaño y tipo de localidad. La interpretación del dinamismo económico-demográfico de la región que se presenta en el apartado anterior, obviamente requiere de comprobación empírica. Esta comprobación será objeto de investigación de campo; sin embargo, una primera aproximación - a manera de prueba de hipótesis- puede llevarse a cabo a partir del análisis de datos censales.

$\mathrm{Si}$ la relación que guardan en la estructura productiva los principales grupos de trabajadores (ejidatarios cañeros, ejidatarios no cañeros y jornaleros) se da en los términos en que se ha interpretado, entonces pueden derivarse algunos supuestos respecto del tamaño y crecimiento de la población de los distintos tipos de localidades:

32 Véase P. Singer, "Migraciones internas: consideraciones teóricas sobre su estudio", Economía politica de la urbanización, México, Siglo XXI Editores, 1975, pp. 31-70, y la crítica a este artículo propuesta por B. García "El estudio de la dinámica demográfica y el desarrollo agrícola: discusión de algunas contribuciones importantes". México, El Colegio de México, 1975 (mimeografiado).

33 Consideraciones en contra del migrante irlandés en la época de la revolución industrial pueden verse en F. Engels, La situación de la clase obrera en Inglaterra, México, Ediciones Cultura Popular, 1974, pp. 123-127. Una reinterpretación de este fenómeno para el caso de los trabajadores migratorios mexicanos en Estados Unidos puede verse en J. Bustamante, "Espaldas mojadas: materia prima para la expansión del capitalismo norteamericano", México, Cuadernos del CES, No. 9, El Colegio de México, 1975.

34 Véase "La regulación de la tenencia en México", Archivos del IEPES, Núm. 10, México, 1975. 
En primer lugar, se puede esperar que los municipios que tienen un mayor número de sociedades ejidales sean los que reciban un mayor número de emigrantes (jornaleros temporales o definitivos) $\mathrm{y}$, en consecuencia, manifiesten un mayor crecimiento; por el contrario, podemos esperar que los municipios de mayor número de ejidos no cañeros sean los de menor crecimiento, ya que en ellos la emigración determinada por el desarrollo del ciclo familiar no se ve compensada por la emigración de jornaleros.

En segundo lugar, a nivel de localidad particular, se puede suponer que existirá una asociación directa entre el tipo de localidad y el tamaño y crecimiento de su población; esto es, las sociedades ejidales serán de mayor tamaño y tendrán mayor crecimiento, mientras los ejidos no sociedades presentarán la situación contraria.

El peso de la inmigración en los distintos municipios de la región se presenta en el cuadro 7. Este cuadro indica la población que habita en la zona de estudio y que cambió de lugar de residencia según el número de años que tiene de vivir en la región. Al comparar estos datos con los que presenta el cuadro 5 , puede verse que la población inmigrante ha venido a residir a los municipios predominantemente cañeros: Ayala, Jojutla, Zacatepec, Puente de Ixtla y Tlaltizapán (los casos de Jiutepec

\section{Cuadro 7}

ZoNa DE INFLUENCIA DEL INGENIO EMILIANo ZaPATA:

Población Que cambió de lugar de Residencia, SEgún el tiempo QUE TIENE DE RESIDIR EN LA ZONA POR MUNICIPIO, 1970

\section{$(\text { porcientos })^{\mathrm{a}}$}

\begin{tabular}{|c|c|c|c|c|c|c|}
\hline \multirow[b]{2}{*}{ Muniofiptos } & \multirow[b]{2}{*}{$\begin{array}{l}\text { Total do poblacion } \\
\text { procedento de otra } \\
\text { entidad o pais }\end{array}$} & \multicolumn{5}{|c|}{ Años de rosidenoja } \\
\hline & & $\begin{array}{l}\mathrm{De} 11 \\
\text { años } \\
y \text { mán }\end{array}$ & 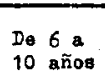 & $\begin{array}{l}\text { De } 1 \text { a } \\
5 \text { añ่os }\end{array}$ & $\begin{array}{l}\text { Menos } \\
\text { de un } \\
\text { año }\end{array}$ & $\begin{array}{l}\text { Perlodo } \\
\text { no } \\
\text { indicado }\end{array}$ \\
\hline Total do la region & 61380 & 26754 & 10788 & 14797 & 6985 & 2056 \\
\hline $\begin{array}{l}\text { Amaouzao } \\
\text { Ayala } \\
\text { Coatlán del Rfo } \\
\text { Jailiano Zapata } \\
\text { Jiutepeo } \\
\text { Jojutla } \\
\text { Jonacatepec } \\
\text { Mazaoatepoo } \\
\text { Mlacatlán } \\
\text { Puento do Ixtla } \\
\text { Temixco } \\
\text { Tepaloingo } \\
\text { Tetecala } \\
\text { Tlaltizapen } \\
\text { Tlaquiltenango } \\
\text { Toohitepeo } \\
\text { Zacatepeo }\end{array}$ & $\begin{array}{r}3.32 \\
10.25 \\
2.86 \\
4.86 \\
14.15 \\
14.72 \\
0.62 \\
1.17 \\
1.58 \\
7.77 \\
10.72 \\
0.91 \\
1.38 \\
6.81 \\
3.77 \\
2.29 \\
12.82\end{array}$ & $\begin{array}{r}2.93 \\
7.83 \\
3.35 \\
4.71 \\
10.84 \\
16.91 \\
0.58 \\
1.61 \\
1.77 \\
9.39 \\
9.27 \\
0.81 \\
1.91 \\
6.87 \\
3.55 \\
2.49 \\
15.18\end{array}$ & $\begin{array}{r}3.57 \\
10.50 \\
2.95 \\
4.88 \\
16.17 \\
15.43 \\
0.56 \\
0.79 \\
1.60 \\
5.99 \\
12.53 \\
1.25 \\
0.86 \\
6.59 \\
2.72 \\
2.06 \\
11.55\end{array}$ & $\begin{array}{r}4.35 \\
10.91 \\
2.38 \\
5.64 \\
16.67 \\
13.26 \\
0.65 \\
0.78 \\
1.49 \\
7.18 \\
12.59 \\
0.81 \\
0.91 \\
6.89 \\
3.41 \\
2.19 \\
9.89\end{array}$ & $\begin{array}{r}2.22 \\
15.62 \\
1.23 \\
4.17 \\
10.05 \\
11.64 \\
0.93 \\
0.97 \\
1.07 \\
4.24 \\
18.81 \\
1.05 \\
1.19 \\
6.87 \\
5.28 \\
1.59 \\
13.07\end{array}$ & $\begin{array}{r}3.45 \\
17.37 \\
5.11 \\
3.50 \\
12.50 \\
3.06 \\
0.34 \\
0.83 \\
1.46 \\
12.40 \\
8.95 \\
0.58 \\
1.46 \\
6.32 \\
9.63 \\
4.09 \\
8.95\end{array}$ \\
\hline
\end{tabular}

Fuente: Censo General de Población, 1970.

a La suma de los porcientos de cada columna para cada período de residencia es igual al 100 por ciento.

b Los diferentes períodos de residencia están referidos a 1970. 
y Temixco con un alto porciento de inmigrantes debido a su condición especial - cercanía con Cuernavaca - caen fuera de nuestro argumento sobre el crecimiento de población municipal). En sentido inverso, puede observarse que los municipios de mayor número de ejidos no cañeros o con menor importancia en el cultivo de la caña son los que han recibido menos población migrante: Tepalcingo, Jonacatepec, Mazatepec, Miacatlán y Tetecala. ${ }^{35}$

Esta población migrante parece ser un factor determinante en el crecimiento de población a nivel municipal. En el cuadro 2 puede observarse que los municipios de mayor inmigración son los de mayor crecimento: Jojutla, Ayala y Zacatepec (Temixco y Jiutepec, como he dicho, no entran en la asociación que hemos supuesto), mientras los municipios de menor crecimiento de población corresponden a los que se mencionaron como de menor inmigración: Tepalcingo, Jonacatepec, Mazatepec, Miacatlán y Tetecala.

El peso de la inmigración en el crecimiento de la población de los distintos municipios es, obviamente, tautológico. Este carácter puede disminuir tomando a la localidad en particular. En el cuadro 8 he tratado de cruzar las variables "crecimiento de población" con el "tipo de localidades por tamaño". Con base en la población de las localidades de la zona en 1970 se han clasificado en cinco grupos de tamaño, y se estima su crecimiento calculando el cambio porcentual, respecto de la región, que habían experimentado a partir de su año de aparición. El número de localidades se redujo a las que tenían categoría de ejidos - sociedades o no sociedades-, y que existían en 1921 o habían aparecido en 1930 o 1940 (véase el apéndice metodológico).

Existe un grado de asociación notable entre el tipo de localidad y su índice de crecimiento. El número de sociedades de alto crecimiento (20 de 59) es mucho mayor que el de los ejidos no sociedades ( 8 de 56); inversamente, el número de ejidos con bajo crecimiento (31 de 56) es mayor que el de las sociedades (17 de 59). ${ }^{36}$

Esta situación no se da en forma semejante en los distintos grupos por tamaño. Hay más localidades grandes de alto crecimiento, mientras que en el grupo de localidades menores predominan las de bajo crecimiento. Esto sucede en los dos tipos de localidades, pero en el estrato donde aparecen casi el mismo número de sociedades y ejidos (estrato $\mathrm{C}$, cuadro 8) es evidente que existe entre las sociedades una mayor propor-

35 No es posible conocer la población que emigra de la zona que estudiamos, ya que esta información en el Censo de Población sólo aparece a nivel de entidad. Sin embargo, como el estado de Morelos es una de las entidades que experimentó una fuerte tasa de emigración en el periodo 1960-1970 (82.3 por mil para hombres y 94.9 por mil para mujeres) es posible suponer que la emigración de la zona de estudio debe ser considerable. Véase $\mathrm{M}$. Ordorica, et al., "Migración interna en México: 1960-1970", Evaluación y análisis, Serie III, Núm. 5, Dirección General de Estadística, Secretaría de Industria y Comercio, 1976.

${ }^{36}$ La prueba $X^{2}$ resultó significativa a un nivel de confianza de $0.95 \%$ en la asociación tipo de localidad e índice de crecimiento. 


\section{Cuadro 8}

ZONA DE INFLUENCIA DEL INGENIO EMILIANO ZAPATA: CRECIMIENTO DE LA POBLACIÓN POR TAMAÑO Y TIPO DE LOCALIDAD

\begin{tabular}{|c|c|c|c|c|c|c|c|c|c|}
\hline \multirow{3}{*}{$\begin{array}{l}\text { Grupos de looalida } \\
\text { dea sogfin ol tama- } \\
\text { no de 1a poolación } \\
\text { (ntmero de habitan } \\
\text { tea) }\end{array}$} & \multirow{3}{*}{$\begin{array}{l}\text { Total de lo } \\
\text { oalidades } \mathrm{a} /\end{array}$} & \multicolumn{8}{|c|}{ Indice do oreoimiento b/ } \\
\hline & & \multicolumn{4}{|c|}{ Soojedadeg ojidalog } & \multicolumn{4}{|c|}{ Sjidos no oociadader } \\
\hline & & $\begin{array}{l}\text { Total so } \\
\text { ciadades }\end{array}$ & Aito & Medio & Bajo & $\begin{array}{l}\text { dos no mo } \\
\text { oiedades }\end{array}$ & Alto & Madio & Bajo \\
\hline Total de la región & 115 & 59 & 20 & 22 & 17 & 56 & 8 & 17 & 31 \\
\hline Más de 5000 & 11 & 11 & 5 & 3 & 3 & - & - & - & - \\
\hline D. 1800 a 4999 & 31 & 24 & 10 & 8 & 6 & 7 & 3 & 1 & 3 \\
\hline Do 800 a 1799 & 29 & 15 & 4 & 9 & 2 & 14 & 1 & 7 & 6 \\
\hline De 375 \& 799 & 17 & 5 & - & 2 & 3 & 12 & 1 & 3 & 8 \\
\hline Do 1 a 375 & .27 & 4 & 1 & - & 3 & 23 & 3 & 6 & 14 \\
\hline
\end{tabular}

Fuente: Cálculos elaborados con datos de las fuentes citadas en el cuadro 5.

a Corresponde a las localidades existentes en 1940 y que tenían categoría de ejido en 1970 . No se incluyen las no especificadas.

b La forma de agrupar los tamaños de población de las localidades y la manera en que se calculó el índice de crecimiento aparecen en el Apéndice metodológico.

ción de localidades de crecimiento alto y medio (13 de 15), y que en los ejidos esta proporción se da en localidades de crecimiento medio y bajo (13 de 14).

En esta primera aproximación a la dinámica demográfica de la zona he buscado sólo eso, acercarme a un problema para encontrar allí preguntas nuevas y más pertinentes.

\section{CONCLUSIONES}

La presión de la población sobre los recursos naturales ha sido motivo de constante discusión de los que analizan los problemas demográficos. En el caso del fenómeno migratorio la "presión demográfica" como determinante de la emigración rural sigue siendo - a pesar de su mecanicismo- un factor de explicación de la migración.

Factores estructurales (de cambio') y factores demográficos (de estancamiento) siguen uno al lado del otro en la interpretación de la migración rural sin que se conozca su interdependencia (véase $\mathbf{P}$. Singer, op. cit.).

En este trabajo, estrictamente empírico, se ha encontrado que la relación entre el crecimiento de la población (desarrollo del ciclo familiar') y los recursos (tamaño de parcela ejidal) toma sentido como "presión demográfica" cuando introducimos la imposibilidad de reproducir las mismas relaciones sociales (hijos de ejidatarios sin acceso a tierra ejidal). En esta forma, los recursos son factores de expulsión en la migración rural-urbana en la medida en que restringe la escala de reproducción de ciertas relaciones sociales. 
El mismo argumento podría pensarse -en forma de hipótesis- para la población proletaria de la región de análisis (jornaleros). No es difícil suponer que el nivel de empleo en las actividades agrícolas de la región tenga un límite (aun suponiendo un nivel de infrasubsistencia para los trabajadores). En esta situación, la cercanía a grandes ciudades seguramente representará una posibilidad de mejorar el nivel de vida. Para los hijos de los jornaleros, en esas circunstancias, la migración rural-urbana sólo significará un cambio de actividad y no un cambio en su condición de asalariado.

La perspectiva de una mayor migración rural-urbana parece una consecuencia lógica, pero sólo una investigación más específica nos podrá dar indicios de su magnitud.

\section{APÉNDICE METODOLÓGICO}

La estimación del crecimiento demográfico a nivel de localidad rural por medio de tasas aritméticas o geométricas pierde significado cuando se tratan localidades pequeñas. En éstas un aumento mínimo de la población se refleja en altas tasas de crecimiento, mientras ese mismo aumento en localidades mayores se expresa en tasas muy bajas.

Con el objeto de disminuir ese sesgo, para medir el crecimiento de población en las localidades que componen la región de estudio, se han introducido dos criterios operacionales para controlar el tamaño de población.

lo. Se han agrupado las localidades según el tamaño de población, de tal forma que los valores dentro de cada grupo sean lo más homogéneos posibles y los grupos entre sí sean lo más diferentes posible. ${ }^{1}$ De esta

1 El método utilizado proporcionado por Rosa María Rubalcaba, fue presentado por J. Nieto de Pascual con el nombre de "Dicotomías sucesivas" y consiste en los siguientes pasos:

i) Los valores para $N$ observaciones (en este caso población de localidades) se ordenan en una escala decreciente:

ii) se definen dos grupos: el primero que sólo contenga a la primera observación y el segundo a todas las demás;

iii) se calcula la "suma de cuadrados entre" de esos dos grupos que mide la variación entre ambos grupos.

Suma de cuadrados "entre" $\stackrel{2}{\Sigma}_{i}^{=} n_{i}\left(\bar{X}_{i}-\bar{X}\right)^{2}$

$i$ es el número del grupo y $n_{i}$ es el número de observaciones que hay en el grupo $i$;

iv) se agrega otra observación al primer grupo y vuelve a efectuarse el paso iii). Si al haber agregado esa nueva observación la "suma de cuadrados entre" es ahora menor que la que teníamos, se considera que esa observación que se había agregado no pertenece en realidad a ese grupo porque hizo que la variación "entre", que queríamos fuese máxima, decreciera, por lo que esa observación inicia un nuevo subgrupo o estrato;

v) a partir de esa observación empezamos nuevamente el procedimiento, que formará otra vez dos estratos con las observaciones restantes. 
manera los distintos niveles de crecimiento de las localidades pueden compararse dentro de cada grupo.

Con este criterio se determinaron los siguientes grupos de localidades según el tamaño de la población que tenían en $1970 .{ }^{2}$
A. De 5968 a 16839 habitantes
B. De 1802 a 4418 habitantes
C. De 823 a 1644 habitantes
D. De 383 a 740 habitantes
E. De 49 a 365 habitantes

2o. Para cada localidad se estimó un índice de crecimiento de población en términos relativos: el cambio en la participación que había experimentado la localidad en la región a partir de su año de aparición. Este cálculo se hizo mediante la siguiente expresión:

$$
\left(P_{70}-P_{0}\right) / P o
$$

Donde: $\mathbf{P}_{70}$ es el porciento de la población de la localidad respecto de la región en el año 1970 , y $P o$ es el porciento de la población de la localidad respecto de la región en el año de su aparición.

El número de localidades analizadas se redujo a las que existían en 1921, y a las que aparecieron en 1930 y 1940; se examinaron en exclusiva las que tenían categoría de ejido: sociedades ejidales y ejidos no sociedades (véase el cuadro 8 ).

Se tomaron como localidades de alto crecimiento las que habían aumentado su participación (en el periodo de análisis) en $33 \%$ o más y como de bajo crecimiento las que la habían perdido en ese mismo porcentaje o más. Como de crecimiento medio se definieron las localidades que se encontraban dentro de esos valores.

2 En el cuadro 8 estos grupos de tamaño se presentan como si fuesen continuos. En la región, obviamente, no se presenta ese continuum en el tamaño de población de las localidades. 